\title{
Nuevas lecturas sobre la pintura religiosa de Antonio María Esquivel (1806-1857), sus fuentes y su fortuna crítica
}

\author{
New readings on the religious painting of Antonio María Esquivel \\ (1806-1857), its sources and critical fortune \\ Pedro J. MARTÍNEZ PLAZA \\ Museo del Prado
}

ORCID: https://orcid.org/0000-0002-2328-4371 / pedroj.martinez@museodelprado.es DOI: http://dx.doi.org/10.18002/da.v0i19.5984

Recibido: 21-VIII-2019

Aceptado: 7-V-2020

RESUMEN: El estudio de las iconografías religiosas de Esquivel, muchas de las cuales resultan de gran originalidad en la pintura española de su tiempo, permite conocer sus referentes -que en ocasiones se encuentran en el extranjeroy su fortuna crítica, así como sugerir nuevas hipótesis de interpretación para algunas de ellas y dar a conocer otras obras hasta ahora inéditas.

Palabras clave: Antonio María Esquivel; Pintura sevillana; Iconografía cristiana; Antiguo Testamento; Nuevo Testamento; Santa Teresa de Jesús; San Miguel Arcángel; Angelología.

ABSTRACT: The analysis of the religious iconographies of Esquivel, many of which are of special originality in the Spanish painting of his time, reveals his referents - which refer in some cases to foreign painting - and his critical fortune. Furthermore, this article suggests a new interpretation about some of Esquivel's paintings, some of which remain unpublished until today.

Keywords: Antonio María Esquivel; Sevillian painting; Christian iconography; Old Testament; New Testament; Saint Teresa of Jesus; Saint Michael the Archangel; Angelology.

El pintor sevillano Antonio María Esquivel, considerado uno de los nombres fundamentales del romanticismo español, desarrolló la mayor parte de su carrera en Madrid, donde estuvo vinculado a la Academia de Bellas Artes de San Fernando y al Liceo Artístico y Literario y disfrutó de la consideración de una extensa y variada clientela ${ }^{1}$.

\footnotetext{
${ }^{1}$ Este artículo tiene como punto de partida la conferencia que el autor impartió en el Museo del Prado el 20 de octubre de 2018. Esta tuvo lugar con motivo de la
}

Fue un excelente retratista y autor de cuadros de composición y se le puede considerar como el pintor religioso más relevante de su tiempo, no solo por el gran número de

Presentación de Colecciones titulada Antonio María Esquivel (1806-1857). Pinturas religiosas (julio de 2018 - enero de 2019), comisariada por Javier Barón. Agradezco la ayuda prestada por el párroco de la Iglesia Matriz del Salvador en Santa Cruz de la Palma, el párroco de La Puebla de Montalbán y Rodolfo de los Reyes, Alejandro Ancalao, Isabel Argerich, Olatz Berasategui, Ignacio Hermoso y Francisco J. Morales. 
obras que, a lo largo de su trayectoria, dedicó a este género, sino muy especialmente por las numerosas aportaciones y novedades que aquellas supusieron dentro del panorama artístico nacional y por la especial trascendencia que muchas alcanzaron ${ }^{2}$. Sin embargo, el estudio de esta parte de su catálogo ha estado dominado por cuestiones netamente formales, analizadas a partir de su vinculación con el murillismo y el purismo ${ }^{3}$. Estas lecturas han obviado otras igualmente interesantes, basadas en los propios asuntos representados y en el modo en el que fueron abordados por el artista y por algunos de sus coetáneos y seguidores. Esto permite ofrecer nuevas interpretaciones sobre las obras o ejemplos que pudieron servirle de modelo, así como estudiar pinturas suyas hasta ahora inéditas o erróneamente catalogadas, junto con otras copias que se hicieron de algunas de ellas y que permanecían ignotas. Conocer el destino que tuvieron estas pinturas resulta fundamental para este estudio, pues permite distinguir dos grandes grupos de obras religiosas según fueran realizadas para la devoción o para las exposiciones públicas y la docencia.

\section{LAS PINTURAS REALIZADAS PARA LA DEVOCIÓN PÚBLICA Y PRIVA- DA}

En una de las primeras noticias de relevancia tras la llegada de Esquivel a la Corte en 1831, se señalaba que sus éxitos habían

\footnotetext{
${ }^{2}$ Entre los estudios sobre este pintor deben destacarse: Bernardino de Pantorba, "Antonio María Esquivel", Arte Español, T. XXII (1959), 155-179; José Guerrero Lovillo, Antonio María Esquivel (Madrid: CSIC, 1957); Antonio de la Banda y Vargas, Antonio María Esquivel (Sevilla: Diputación Provincial, 2002) y también Enrique Valdivieso, Pintura sevillana del siglo XIX (Sevilla: el autor, 1981), 34-41; Enrique Valdivieso, Historia de la pintura sevillana: siglos XIII al XX (Sevilla: Guadalquivir, 1986), 366-371 y Enrique Valdivieso y José Fernández, Pintura romántica sevillana (Sevilla: Fundación Sevilla Endesa, 2011), 100-114.

${ }^{3}$ Véase fundamentalmente Gerardo Pérez Calero, "Consideraciones estéticas en torno a la obra del pintor Antonio M. Esquivel", Laboratorio de Arte, no 24 (2012), 527-536.
}

venido de lo que luego se denominó "la extraordinaria facilidad y singular parecido de sus retratos al óleo" ${ }^{\prime 4}$. Este testimonio, hasta ahora desconocido, ofrece nuevas razones acerca de su pronta reputación en esta especialidad. En 1836, el pintor Valentín Carderera, preocupado por su futuro profesional, escribía a Madrid a su compañero Federico de Madrazo lo siguiente: "ruego me diga si cree que ahí podría hacer algunos retratos aunque fueran baratos, no tanto como los de Esquivel y Gutiérrez etc." ${ }^{5}$. Parece por tanto que su temprano éxito se debía a su capacidad para llegar a un público más modesto con retratos asequibles, pues hasta 1837 se dedicó al género religioso solo de forma circunstancial. Así, en 1832 presentó Jacob bendice a Efraín y Manasés (Madrid, Academia de San Fernando) como parte de su ingreso en la Academia de Bellas Artes. Esta obra, que puede considerarse de momento su primera incursión en el género, careció de continuidad y su conocimiento se limitó al ámbito académico en que se produjo.

Un año más tarde recibió su primer encargo de gran envergadura. Se trata de una Magdalena penitente, destinada a la Catedral de Badajoz y pagada a principios de $1833^{6}$. Aunque no se conocen las condiciones del encargo, creemos que en el mismo debió intervenir Pascual Genaro Ródenas, coleccionista y político, que había sido intendente de la provincia de Badajoz durante el Trienio Liberal y que hubo de conservar allí algunos conocidos tras su vuelta a Madrid. Posiblemente él pudo acudir a su amigo, el también coleccionista Manuel López Cepero, para que este hiciera el encargo a Esquivel,

\footnotetext{
${ }^{4}$ Luis Villanueva, "Don Antonio María Esquivel", Museo de las Familias, T. II (1844), 90-93.

${ }^{5}$ Archivo del Museo del Prado (AMP), Carta de Carderera a Madrazo, Madrid, 12 de septiembre de 1836.

${ }^{6}$ Francisco Tejada Vizueta, “Las artes plásticas. La pintura", en La catedral de Badajoz. 1255-2005, coord. por Francisco Tejada Vizueta (Badajoz: Tecnigraf Editores, 2007), 486 (con bibliografía anterior).
} 
a quien ayudó desde su llegada a la Corte 7 . El hecho de que la obra pasase desapercibida para sus primeros biógrafos indicaría que fue enviada a su destino nada más ser acaba$\mathrm{da}$, sin ser expuesta, y que, tras su entrega, Esquivel siguió dedicándose al retrato. Por lo demás, el gran lienzo es esencial para tratar de reconstruir su producción religiosa, ya que muestra la práctica totalidad de recursos compositivos que la marcarán desde entonces. Las entonaciones doradas y anaranjadas construyen los fondos y los cielos y estos aparecen poblados de numerosos querubines, que en otras ocasiones estarán acompañados de ángeles. La ausencia de cualquier tipo de halo o corona como signo de santidad de las figuras representadas también se observa en ocasiones en otros artistas sevillanos, como José Gutiérrez de la Vega, pero en el caso de Esquivel se convierte en algo casi normativo. La composición muestra también las referencias a la pintura barroca española que definirán, más que ningún otro tipo de recurso, sus grandes obras y que a menudo han servido para definir al artista como fiel defensor de los preceptos de la pintura española, que en casos como este se convierten en los más eficaces y útiles para resolver con solvencia un encargo con un fin devocional muy concreto.

De un modo parecido resolvió la siguiente gran obra destinada a un lugar de culto. Se trata de la Transfiguración (de 1837), para la iglesia de El Salvador (actual Parroquia Matriz de El Salvador) de Santa Cruz de la Palma. Aunque se ha señalado que el precedente más cercano y próximo es la obra homónima de $\operatorname{Rafael}^{8}$-con la cual apenas guarda relación compositiva o iconográfica-, creemos que Esquivel más bien manejó otras fuentes, como determinadas estampas flamencas y alguna otra que reproducía el lienzo con este tema de Tiziano que se conserva en la iglesia del Salvador en Venecia, o bien

\footnotetext{
7 Pedro J. Martínez Plaza, “Manuel López Cepero (1778-1858) y la pintura sevillana de su tiempo", Laboratorio de Arte, no 29 (2017), 556.

${ }^{8}$ Pérez Calero, “Consideraciones estéticas...", 531.
}

se inspiró en ciertas representaciones escultóricas andaluzas. La posición de los brazos de Cristo, con una mano hacia el cielo y otra hacia la tierra, se observa de hecho en esos grabados, pero no en pinturas españolas o italianas, en las que se le suele representar mostrando las palmas de las manos extendidas a la misma altura.

La obra tiene otras particularidades que la convierten en una de las interpretaciones más singulares de este asunto y que han llevado incluso a pensar que tanto el lienzo como el retablo donde fue colocado están vinculados a la ideología masónica9. Entre ellas, destaca la presencia de Dios Padre en la parte superior, lo cual no solo resulta ajeno a la tradición iconográfica de este asunto (apenas se puede destacar algún estudio de Rubens en el Louvre donde también aparece la figura de Dios) sino que además supone una libre interpretación de los textos evangélicos. La espada flamígera que porta Elías, un atributo que sí es habitual en las representaciones individuales del profeta, resulta también extraña. De hecho, solo puede destacarse la figura de Elías en la Transfiguración del retablo de San Miguel de Jerez de la Frontera de Juan Martínez Montañés, conjunto que el pintor quizá desconocía. Como en el caso de la Magdalena de Badajoz, aunque se conocen las condiciones del encargo, se ignora quién pudo servir de nexo entre el comitente y Esquivel. La obra fue encargada a iniciativa de Manuel Díaz Hernández, un sacerdote canario conocido por su defensa de los ideales liberales, al igual que sus paisanos José y Bartolomé Martínez de Escobar. Es posible que, a petición de Manuel Díaz, José Martínez acudiese al también liberal López Cepero -que era su amigo y a quien envió numerosas cartas desde Canarias ${ }^{10}$ -

\footnotetext{
${ }^{9}$ Jesús Pérez Morera, “Simbología masónica del retablo mayor de la Iglesia de El Salvador de Santa Cruz de la Palma (Canarias)", Cuadernos de Arte e Iconografía, no 8 (1991), 260-266.

${ }^{10}$ Las tres cartas conocidas están fechadas en 1821 y fueron enviadas por José Martínez de Escobar desde Canarias: Archivo de la Provincia Bética Franciscana, Espartinas (Sevilla), Archivo del Deán Lopez-Cepero
} 


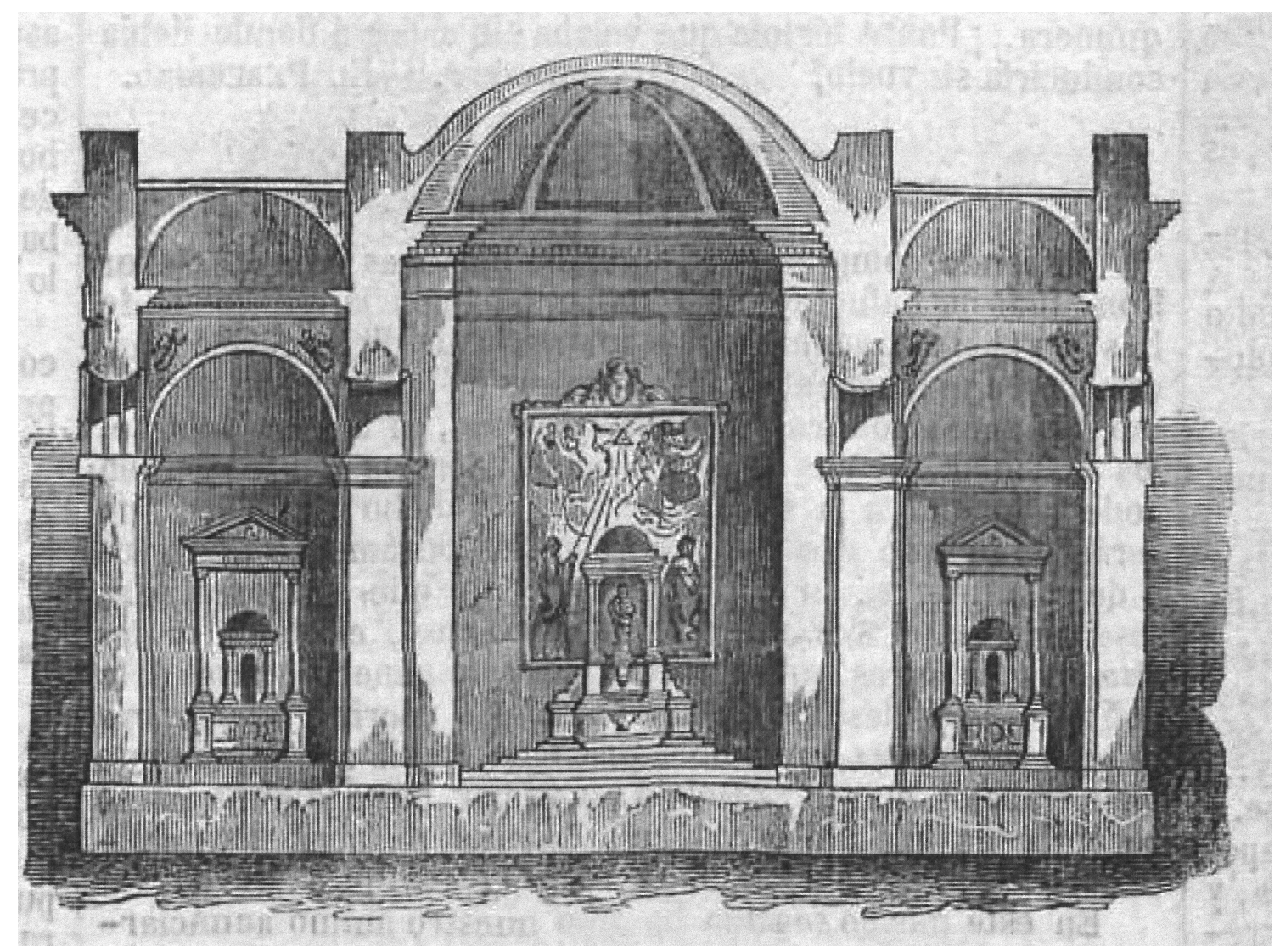

- Fig. 1. Cabecera de la iglesia de Chamberí con el cuadro de Santa Isabel y Santa Teresa, según grabado aparecido en La Ilustración, 23 de noviembre de 1850, p. 376.

para mediar en el encargo, y que Cepero pensara de nuevo en su protegido Esquivel, quien además compartía similares planteamientos políticos con todos ellos.

Sin tener en cuenta los apóstoles destinados al coro de la catedral de Sevilla de $1837^{11}$, el siguiente gran encargo religioso le llegó a Esquivel al final de su vida (hacia 1850) e iba destinado a la nueva iglesia dedicada a Santa Teresa y a Santa Isabel en el barrio de Chamberí (Madrid). El lienzo, no conservado, era el de mayores dimensiones de toda la producción de Esquivel, medía cinco metros de alto y las figuras eran mayores que el natural. Conocemos su aspecto original gracias a una ilustración grabada publicada el mismo año de su finalización (Fig. 1) y a

(ADL-C), 27/9 y 27/64. Cabe pensar que la amistad continuó en la década siguiente.

${ }^{11}$ Sobre este encargo véase Martínez Plaza, "Manuel López Cepero...", 546-552. una descripción de ese mismo momento ${ }^{12}$. Según esta, Santa Isabel se disponía a la izquierda, y tenía a sus pies dos ángeles: "uno sostiene una bandeja de donde toma el otro monedas que derrama y esparce al aire". La inclusión de esta alegoría, alusiva a la caridad que caracterizó la vida de la santa reina, resulta de nuevo insólita y carece de precedentes iconográficos en las representaciones de la misma. Puesto que el centro del lienzo quedaba oculto por un baldaquino exento, la Santa Teresa se colocaba en el lado derecho, en actitud de recibir el Espíritu Santo. De nuevo resulta novedosa la presencia de dos ángeles, uno de los cuales le sujeta el libro en el que escribe, mientras otro muestra un segundo libro al fiel. La mitad superior, más

\footnotetext{
${ }^{12}$ La Esperanza, 9 de noviembre de 1850. La descripción es recogida en Jaime Castillo, La iglesia de Chamberí (Madrid: Edieco S.L., 1999), 36.
} 
convencional, mostraba numerosos ángeles rodeando al Espíritu Santo.

En una de las necrológicas publicadas a la muerte de Esquivel, se menciona entre sus obras una Santa Teresa para "un propietario de Chile" ${ }^{13}$, de cuya existencia se han hecho eco los biógrafos del artista, si bien limitándose a mencionarla ${ }^{14}$. La obra, en efecto, se conserva aún en uno de los altares laterales de la iglesia del Monasterio de San José (municipalidad de Nuñoa, Santiago, Chile), y se encuentra firmada y fechada en 1856 (Fig. 2). Aunque desconocemos las circunstancias del encargo, la composición parece derivar del cuadro grande de Chamberí y recuerda también a la que repite en otras obras de estos años, como la Virgen María, el niño Jesús y el Espíritu Santo con ángeles en el fondo del Museo del Prado. La santa aparece rodeada de diferentes angelitos, que se reparten sus atributos: el birrete, los libros, el tintero, el rosario y la cruz, que, a diferencia de lo habitual, no incorpora a Cristo crucificado.

El último gran encargo de carácter devocional debió ser el conocido como Cristo de Quitapesares (Sevilla, Museo de Bellas Artes), que la reina María Cristina de Borbón quería colocar en su palacio de Quitapesares, en Palazuelos de Eresma (Segovia). Se trata de una obra de gran tamaño, que muestra a Cristo con faldellín y la estola colgando de la cruz. Creemos que se trata del mismo que algunas necrológicas identificaron como su última obra ${ }^{15}$ : al sobrevenirle la muerte a Esquivel, el cuadro nunca llegó a su destinatario, y por eso Carlos María Esquivel Hiráldez, su nieto, lo ofreció en venta al Estado en 1882, describiéndolo entonces como "más que de tamaño natural"16.

${ }^{13}$ El Museo Universal, 15 de abril de 1857.

${ }^{14}$ Tan solo se ofrece su localización exacta en Banda, Antonio María Esquivel..., 86.

${ }^{15}$ En El Museo Universal, 15 de abril de 1857, se señala que el tamaño de esa obra era de tres varas, que coincide con el alto del cuadro del Museo, cuyas medidas son: $297 \times 169,5 \mathrm{~cm}$.

${ }^{16}$ Archivo de la Real Academia de Bellas Artes de San Fernando (ARABASF), leg. 4-61-1: La Academia in-

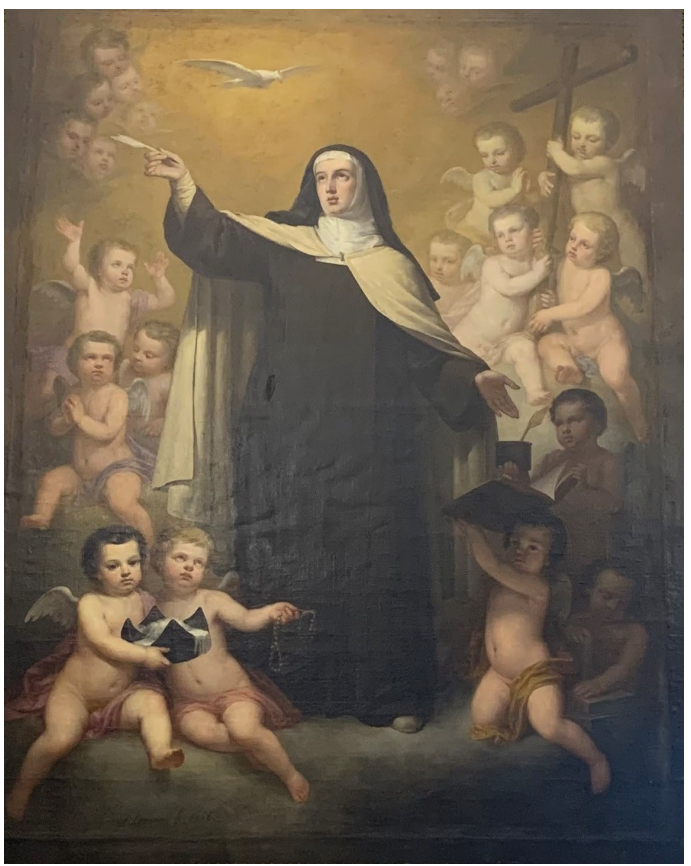

- Fig. 2. Antonio María Esquivel. Santa Teresa. 1856. Iglesia del Monasterio de San José, municipalidad de Nuñoa, Santiago, Chile. Foto del autor.

Junto a estas obras de gran empeño destinadas al culto, Esquivel realizó otras de menor tamaño, dirigidas a la devoción privada, que suelen representar figuras de santos. Suponen un grupo bastante homogéneo, pues el formato y las medidas (la mayoría de 125 x 93 centímetros) se repiten sin apenas cambios durante más de dos décadas: el santo se presenta de frente, de medio cuerpo, porta sus atributos en las manos y emerge de un fondo neutro donde dominan las entonaciones doradas, que se aclaran en la zona central para resaltar así el rostro de la figura. De ninguna de ellas consta el encargo, pero casi todas están documentadas desde antiguo en colecciones particulares, por lo que si además tenemos en cuenta lo pródigo que llegó a ser su pincel con este formato cabe pensar que se especializó en él debido a que gozaron de fácil salida entre la burguesía, al cabo su clientela principal. Entre ellos destacan San Miguel Arcángel (Museo Diocesano de

formó en contra de su adquisición, porque: “No prueba este cuadro el reconocido talento del artista, porque es muy inferior a otras obras conocidas de su mano". 
Ciudad Rodrigo), San Hermenegildo, San Lorenzo y Santa Isabel (todos en colección particular); también recurrió a este formato en las Inmaculadas (Museo de la Habana y mercado del arte, 2012), de las que, al contrario que otros pintores sevillanos contemporáneos, no se tiene constancia de ninguna imagen de cuerpo entero, e incluso en una Anunciación, dividida en dos cuadros (Sevilla, Museo de Bellas Artes).

Deben excluirse de este grupo sus representaciones de la Magdalena, que es, por otro lado, el único tema junto con los ángeles y las Vírgenes con niño que repite y versiona a lo largo de su carrera. A través de ellas muestra su peculiar inventiva, capaz de ofrecer en cada caso una interpretación totalmente diferente, variando las vestimentas, el tipo femenino, sus gestos y la posición de los atributos. Aunque Banda señala tres ejemplos distintos ${ }^{17}$, en realidad son cuatro los cuadros conocidos con este asunto: el citado de Badajoz (un encargo), el del Museo de Bellas Artes de Sevilla -de 1843- y que Banda confunde con el del Museo de la Habana -de 1856- y un cuarto, que solo conocemos por una fotografía inédita, de hacia $1844^{18}$. Este último es el único que no incluye la cruz como atributo de la santa. Si comparamos cualquiera de estas interpretaciones con las que hizo su paisano y compañero José Gutiérrez de la Vega (por ejemplo María Magdalena despojándose de sus joyas, Dallas, Meadows Museum) podrá constatarse fácilmente cómo Esquivel prefiere una imagen de la santa como penitente, despojada de todo recuerdo al barroco sevillano, o incluso español -que en la obra de Gutiérrez remite sobre todo a Juan de Valdés Leal-, y fuera de toda afectación y referencia a la tradición del Siglo de Oro.

\section{LAS PINTURAS REALIZADAS PARA LAS EXPOSICIONES PÚBLICAS Y}

\footnotetext{
${ }^{17}$ Banda, Antonio María Esquivel..., 85.

${ }^{18}$ Universidad de Sevilla, Fototeca, inv. 014707.
}

\section{COMO MODELO PARA LOS ALUM-} NOS

Como se ha visto más arriba, desde su llegada a Madrid y hasta 1837, Esquivel se dedicó al género religioso únicamente cuando medió algún encargo. Es posible que el éxito conseguido con la Transfiguración en ese año le animase a llevar con más frecuencia asuntos de este género al gran formato, a pesar de que su salida comercial era siempre menos fácil que el retrato y que otros temas propiamente históricos. Así lo recogía un reputado crítico en 1849 , en sus observaciones sobre las pinturas de asunto bíblico que el sevillano había presentado en la Exposición de la Academia: "merece elogiarse la decisión del señor Esquivel para pintar asuntos históricos, cuando solo los retratos son los que proporcionan algún beneficio positivo $^{\prime \prime 19}$. Aunque hasta ahora no se ha reparado en este hecho, muchas de estas obras nunca llegaron a ser vendidas, quedaron en el taller del artista o fueron regaladas por él a personas de su confianza ${ }^{20}$. Así, a su muerte, una crónica reseñaba que el pintor había fallecido dejando "algunos lienzos que en otros tiempos hubieran ocupado un lugar en los severos claustros de los conventos o en las espaciosas naves de las catedrales" ${ }^{\prime 21}$. Entre estos debían encontrarse, al menos, cuatro obras que décadas más tarde aún conservaban sus descendientes.

En 1886 el pintor Marcos Hiráldez Acosta, que se había casado con Julia Esquivel Rivas, la hija del artista, ofreció cuatro obras de gran tamaño en venta al Estado ${ }^{22}$ : El Salva-

${ }^{19}$ Eduardo Velaz de Medrano, "Revista de Nobles Artes. Esposicion [sic] de pinturas, articulo I", La España, 7 de octubre de 1849.

${ }^{20}$ Entre ellos puede mencionarse el "cuadro que representa un asunto bíblico" que regaló a un discípulo suyo, y que éste conservaba años después (El Contemporáneo, 25 de octubre de 1863).

${ }^{21}$ La Esperanza, 5 de abril de 1858, 3.

${ }^{22}$ ARABASF, leg. 4-61-2. El informe, de 21 de junio de 1886, estima que el Salvador debía adquirirse para el Museo Nacional y los otros tres para museos provinciales. 
dor, la Casta Susana, el Casto José y Agar e Ismael. Podría pensarse que estas quedaron en manos de sus herederos porque el pintor nunca pudo venderlas debido a su gran tamaño. Pero en realidad algunas de estas obras funcionaban como dechados para la formación de los jóvenes artistas, que Esquivel persiguió siempre con especial afán. Téngase en cuenta, por ejemplo, que el Salvador mencionado (la única obra de las cuatro que adquirió el Estado y que hoy se encuentra en el Museo del Prado), a pesar de sus dimensiones y de lo ambicioso de la obra, nunca llegó a exponerse en vida del pintor. Aunque a nivel iconográfico supusiese una reinvención del tema del Salvator Mundi, que se acompaña aquí de Dios Padre y del Espíritu Santo, su principal interés estaba en el estudio de la anatomía y de la guardarropía, dos de las materias sobre las que el sevillano puso más interés como formador de jóvenes artistas. Que las composiciones religiosas del sevillano funcionaron a menudo como modelo formativo lo muestra también la petición de Murillo Bracho, que solicitó un par de obras para la Academia de Cádiz con ese mismo fin: José y la mujer de Putifar y Susana y los viejos (hoy en Sevilla, Museo de Bellas Artes) $)^{23}$.

Estas dos últimas pinturas forman parte de un grupo homogéneo de composiciones religiosas, ejecutadas frecuentemente sin un encargo previo, y que constituyen el grueso de su producción en este género. Puede comprobarse que la gran mayoría tienen un tamaño y formato similares, siempre vertical y con aproximadamente 215 centímetros de alto por un metro y medio de ancho, lo cual dificultaba su venta a particulares. Tienen gran interés para el estudio de Esquivel: en primer lugar, porque el hecho de que constituyan un grupo tan nutrido demuestra que el sevillano, que podía haber elegido un género como la pintura de historia o la mitología, se decantó por este otro para, sin

\footnotetext{
${ }^{23}$ Pelayo Quintero, "Cuadros inéditos de José [sic] María Esquivel que se conservan en Cádiz", Boletín del Museo de Bellas Artes", no 7 (1923), 79-88.
}

la presión de sujetarse a un encargo o a los deseos del comitente, trabajar de forma libre, pudiendo incorporar así muchas de sus conquistas estéticas, formales e iconográficas con las que sentar cátedra en el Liceo o en la Academia; en segundo lugar porque es en estas obras donde de forma más clara se aprecia la cercanía con la pintura extranjera contemporánea, y de un modo particular con la escuela francesa. Esta segunda cuestión hasta ahora sólo había sido tímidamente sugerida ${ }^{24}$, en base a una apreciación concreta que hizo Pedro de Madrazo de su obra Abraham expulsando a Agar e Ismael (mercado del arte, 2013 $)^{25}$, pero se revela fundamental en la producción de Esquivel, como se verá ahora, y obliga a plantear nuevas interpretaciones sobre la misma. La obra de Abraham recordaba a este crítico a una homónima de Horace Vernet, pintada diez años antes (Nantes, Museo de Bellas Artes), y con la cual, en efecto, existen grandes paralelismos en la composición y en la disposición de los personajes y de otros elementos, lo que induce a pensar que Esquivel pudo conocerla. En ambas, Abraham señala con una de sus manos el camino del destierro y con la otra toca levemente al niño, al que agarra con fuerza su madre con la mano derecha mientras sujeta un cántaro en su izquierda.

La cruel historia de Agar y de su hijo Ismael le interesó en otras dos ocasiones: una, inédita, firmada y fechada en 1847 (Fig. 3) y otra, de 1856, en el Museo Nacional del Romanticismo. La primera, que fue vendida erróneamente como una representación de $\mathrm{La}$ Caridad $^{26}$, se corresponde con la que Guerrero Lovillo citó sin precisar identificación ni localización como Ismael muriendo de sed en el desierto ${ }^{27}$. Muestra a Agar en

\footnotetext{
${ }^{24}$ Pérez Calero, “Consideraciones estéticas...", 533.

${ }^{25}$ Pedro de Madrazo, "Esposición [sic] de pinturas de 1847. Artículo II", Semanario Pintoresco, $\mathrm{n}^{\circ} 46$ (1847), 362. La obra fue subastada en Christie's Londres, 26 de noviembre de 2016, lote 26 .

${ }^{26}$ Subastas Fernando Durán, Madrid, 30 de mayo de 2001, lote 961 .

${ }^{27}$ Guerrero, Antonio María Esquivel..., 25.
} 


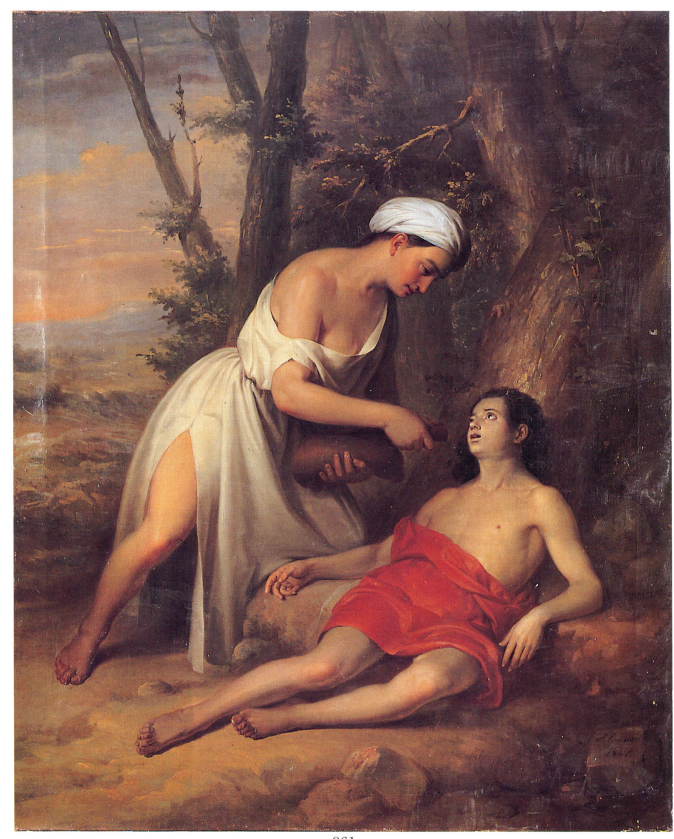

- Fig. 3. Antonio María Esquivel. Ismael muriendo de sed en el desierto. 1847. Colección particular. Foto del autor.

el desierto dando de beber a su joven hijo, completamente desfallecido: el tipo humano de la madre y su indumentaria -tanto el turbante como el detalle que deja casi al descubierto su seno derecho- es similar al del cuadro de Abraham ya citado. La versión del Museo del Romanticismo remite de forma más clara a ejemplos similares de artistas extranjeros pintados con anterioridad, como François Joseph Navez (Agar e Ismael, 1820, Reales Museos de Bruselas) y Charles Locke Eastlake (1830, Londres, Royal Academy of Arts). Además, ha de tenerse en cuenta que este tema había sido casi inexistente entre sus contemporáneos españoles ${ }^{28}$, y careció de interés posteriormente, pues tan solo Nicasio Sentenach lo volvió a emplear para un certamen de relevancia: la Exposición Nacional de Bellas Artes de $1884^{29}$. Por tanto,

${ }^{28}$ Solo se puede destacar "un cuadro de composición que representa al patriarca Abraham despidiendo a la esclava Agar" presentado por Luis Velasco en 1842 en la Academia. Citado en Esperanza Navarrete, $\mathrm{La} \mathrm{Aca-}$ demia de Bellas Artes de San Fernando y la pintura en la primera mitad del siglo XIX (Madrid: FUE, 1999), 490.

${ }^{29}$ Con el número 661 presentó una obra titulada "Agar en el desierto" (medidas: 1.80 x $2.36 \mathrm{~m}$ ). no cabe duda de que sus versiones sobre la historia de Agar e Ismael están influidas directamente por la pintura francesa, que bien pudo conocer durante su estancia en el país vecino durante 1841, la única hasta ahora documentada ${ }^{30}$. El capítulo de la estancia en Francia del pintor es, de hecho, una de las lagunas más importantes en su biografía, y aunque se han realizado algunas nuevas pesquisas sin éxito ${ }^{31}$, tan solo la referencia documental aludida y la existencia de estas y otras pinturas relacionadas con modelos extranjeros permite avanzar en este aspecto.

El libro del Génesis, frecuente en la pintura de la primera mitad del siglo XIX, sirvió de inspiración al pintor en otras ocasiones y se convirtió, junto con otros libros del Antiguo Testamento, en fuente habitual, a diferencia de su escaso interés por el Nuevo Testamento ${ }^{32}$. Destaca la historia de Caín y Abel, que trataron por entonces Juan Rodríguez (en La Maldición de Caín, presentada en la Academia en 1841) y José de la Revilla (en Caín y su familia, después de la maldición divina, 1838, Museo del Prado); Esquivel pintó La Muerte de Abel, que presentó en 1838 en el Liceo, y del que se desconoce su paradero. La carta que envió a Cepero, su protector, dando cuenta del mismo, es por ahora la única aproximación al mismo y permite sugerir como título más certero el de Adán y Eva encuentran el cadáver de Abel: "S.M. la Reyna [sic] Gobernadora me ha comprado otro de dos varas que representa cuando Adán y Eva hallaron el cadáver de Abel y me ha dado por él cuatro mil reales" ${ }^{\prime \prime 3}$.

${ }^{30}$ Martínez Plaza, "Manuel López Cepero...", 557.

${ }^{31}$ Esquivel no aparece en los registros de pasaportes del consulado de Bayona (Archivo General de la Administración -AGA-, Exteriores, Libros 71-73), los únicos con destino a Francia que se conservan y donde aparecen otros compatriotas que viajaron a Francia entre 1830 y 1860.

32 Tan solo en la exposición de 1849 presentó obras basadas en los Evangelios: El milagro de la hija del viudo de Nain, Cristo resucitando a la hija de Jairo (ambas en paradero desconocido) y Cristo en casa de Marta y María (Sevilla, Convento de Santa Paula).

${ }^{33}$ ADL-C, leg. 8/1, Carta de Esquivel a Cepero. 


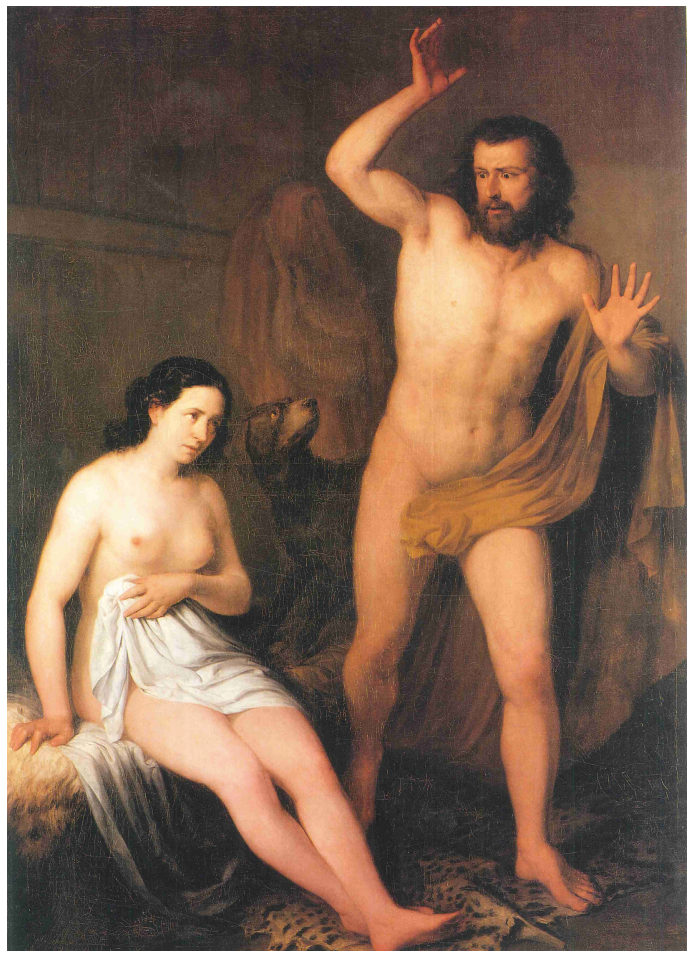

- Fig. 4. Antonio María Esquivel. Jacob en el acto de reconocer que Labán le ha entregado por esposa a Lía en lugar de Raquel (antes titulado Adán y Eva). 1842. Museo de Bellas Artes de Sevilla, inv. CE0404P.

En 1846 presentó el Sacrificio de Isaac (Patrimonio Nacional, Palacio de Riofrío). De nuevo, ofrece su propia interpretación de uno de los temas fundamentales de la pintura occidental, donde habitualmente el ángel detiene con sus brazos a Abraham, que aparece agarrando a su hijo con una mano y con la otra empuñando el cuchillo del sacrificio. Esquivel, en cambio, muestra al padre de pie, con las manos cruzadas sobre el pecho, en el momento en el que asume el mandato del ángel. Ninguna de las tres figuras se toca con otra, sino que cada una presenta un ensimismamiento muy particular, que otorga al conjunto una serenidad y quietud hasta entonces ignotas para este asunto.

La obra muestra además cómo Esquivel suele mantener gran contención a la hora de expresar los sentimientos y las emociones de sus personajes, normalmente muy medidos. Estos sólo se muestran de una forma más rotunda en ocasiones muy concretas, y nor- malmente porque así lo requiere el planteamiento argumental del tema elegido. Es el caso de Jacob en el acto de reconocer que Labán le ha entregado por esposa a Lía en lugar de Raquel (Fig. 4). Esta pintura, firmada y fechada en 1842, había sido catalogada erróneamente hasta aquí como Adán y Eva expulsados del Paraíso. Sin embargo, aparece ya recogida por Ossorio, quien indica que una obra con ese título fue premiada en $1842^{34}$, lo que coincide con la data del cuadro. Además, este, que hasta ahora no había sido identificado por ningún biógrafo ${ }^{35}$, no se ajusta a ningún episodio concreto de la vida de los primeros padres, y sí a la de Jacob, tal y como se narra en el Génesis (29: 17-25). Labán había prometido dar a Jacob a Raquel, su hija menor, y ofreció un banquete para celebrarlo. El lienzo muestra el momento en el que Jacob acaba de descubrir que ha yacido toda la noche con Lía, hermana mayor de Raquel, y no con esta, que era a quien él deseaba. La mirada del hombre y la forzada gesticulación de sus manos muestran su sorpresa; el espacio doméstico que se describe, con un lecho del que huye Jacob, recrea el interior de la tienda y resulta, además, totalmente ajeno a la historia de Adán y Eva, que suele desarrollarse al aire libre y en cuya hagiografía resulta imposible encajar un episodio con esas características.

Hay otra composición de gran tamaño, presentada al Liceo en 1848 pero desconocida hasta su aparición en el mercado en 2017, en la que estos sentimientos se muestran de una forma más rotunda. Su Judit entregando la cabeza de Holofernes (ahora en Madrid, Museo del Romanticismo), destaca precisamente por los rostros de Judit y su sirvienta, que muestran con especial sinceridad la actitud de cada una de ellas ante la atrocidad cometida. Hasta entonces Judit se había mostrado normalmente victoriosa y segura de su de-

${ }^{34}$ Manuel Ossorio, Galería de artistas españoles del siglo XIX (Madrid: Imprenta de Moreno y Rojas, 18831884), 207.

${ }^{35}$ Banda (Antonio María Esquivel..., 79) señala que se encuentra en paradero desconocido. 
cisión $^{36}$. Pero aquí su mirada, que se dirige fuera de la composición, revela miedo e inseguridad ante la posibilidad de ser descubierta, y la posición de su cuerpo indica cierta premura en esconder la cabeza del general asirio. Igualmente, la sirvienta no se muestra complaciente ni impávida, sino sumida en el horror que le produce la contemplación de la cabeza inerte, de la que se aparta de una forma casi exagerada. Resulta relevante que la recepción crítica de esta pintura destacase precisamente estas novedades iconográficas, lo que apenas había sucedido con Esquivel desde la presentación pública de La caída de Luzbel. Un crítico anónimo señalaba: "La figura principal se distingue por la posición propia y elegante, por formas bellas y varoniles, y por la expresión del rostro, que revela la terrible situación del momento"37. Más incisivo, Eduardo Velaz de Medrano afirmó: "la heroína, más que inspirada, parece una mujer criminal que se entretiene en cortar cabezas, como lo hacía últimamente en las barricadas de Paris madame Leblac ${ }^{\prime 38}$.

Dentro de las obras presentadas a las exposiciones públicas ocupan un lugar destacado los temas de ángeles, un grupo más heterogéneo que el anterior, en el que se pueden agrupar pinturas de muy diferente origen, tamaño y formato, y donde la influencia de la pintura extranjera se combina con la española. Es cierto que en Sevilla se había perpetuado la tradición representativa de los siete arcángeles, incluso en el siglo XIX. Sin embargo, el interés de Esquivel por los temas angélicos carece de parangón en su época, pues además él apenas cultivó las ico-

${ }^{36}$ Tan solo puede destacarse Judit camino de Betulia del Museo Diocesano de Jaca, considerada obra de Luis Paret, donde Judit y la sirvienta muestran una actitud parecida a la del cuadro de Esquivel.

${ }^{37}$ El Clamor público, 8 de abril de 1848.

${ }^{38}$ Eduardo Velaz de Medrano, "Revista de Nobles Artes. Esposición [sic] del Liceo. Artículo II (1)", La España, 5 de julio de 1848; citado por Aránzazu Pérez Sánchez, El Liceo Artístico y Literario de Madrid (1837-1851) (Madrid: FUE, 2005), 413. nografías habituales ${ }^{39}$ y cuando lo hizo fue para ofrecer su propia versión. Es el caso de La caída de Luzbel (Museo del Prado), pintado en 1840 tras recobrar la vista, después de un periodo de enfermedad que le había privado de ella. Si se compara con las representaciones tradicionales de San Miguel, e incluso con algunas coetáneas que él debió conocer y de las que se distanció conscientemente -como el San Miguel que pintó Antonio Cabral Bejarano para el encargo ya mencionado del coro de la catedral de Sevilla (colección particular)-, su obra presenta sustanciales novedades. El arcángel aquí aparece despojado de sus característicos atributos, no porta la espada ni el escudo ${ }^{40}$, ni tampoco viste coraza, y además señala al cielo con su mano derecha y se eleva levemente sobre el ángel malo, sin dominarlo ni someterlo.

Se ha dicho que su argumento remite a la literatura contemporánea, en especial de José de Espronceda, pero es posible que el pintor también acudiese a referencias de la pintura del Siglo de Oro que le resultasen familiares. Esto sucede con el San Miguel atribuido a Eugenio Cajés que se conserva en el Monasterio de Santa Paula (Sevilla), que él debió conocer, pues en 1836 había realizado un cuadro con la imagen de su fundadora para este lugar (Ana de Santillán, en el mismo monasterio), lo cual reforzaría la validez de nuestra hipótesis. La figura del arcángel, que pisa con su pie derecho al demonio y levanta levemente la pierna izquierda, tiene una cadencia y una actitud similares, ya que apenas somete al diablo y, además, su mano derecha señala también al cielo. Alrededor de ella, Cajés escribió la sentencia Quis sicut Deus (Quién como Dios) que habitualmente aparece dentro del escudo. Esquivel representa al arcángel mirando a Luzbel mien-

${ }^{39}$ Podría destacarse un Tobías y el Angel, procedente de la Colección Leaniz de Madrid y conocido por fotografía (Instituto del Patrimonio Cultural de España, Fototeca, inv. 17936-B). También puede destacarse otro cuadro presentado en 1844 en el Liceo como Un ángel de la Guarda.

${ }^{40}$ Estas particularidades ya fueron señaladas por Banda, Antonio María Esquivel..., 77. 
tras señala con firmeza al cielo $y$, aunque no incorpora esta frase, ésta se encuentra explícita en la actitud de San Miguel y en la mirada desafiante de su oponente. Este detalle ya fue señalado por José Fernández de la Vega -amigo del artista- en un extenso comentario sobre el cuadro, donde también se indicaban sus muchas novedades iconográficas, aunque sin aludir al lienzo de Cajés que pensamos pudo servirle de referencia: "representa la caída de Luzbel arrojado del cielo por el ángel Miguel, en el momento de decirle ¿Quid sicut Deum?"41. Aunque podría señalarse alguna otra pintura como precedente iconográfico, no se puede asegurar que Esquivel llegase a conocerla. Es el caso de un San Miguel, tenido como obra de Alonso Cano, que se conserva en la actual catedral de Getafe, y que representa al arcángel igualmente sin espada, escudo ni coraza.

Una obra relacionada con Luzbel es El ángel malo (Fig. 5), hasta ahora desconocida ${ }^{42}$. El asunto de este cuadro de gran tamaño (202 x 129 cm.) resulta insólito en la pintura española y está relacionado con las representaciones de El ángel caído, que tan caras fueron en la pintura francesa de las décadas de 1840 y 1850, como muestra el cuadro homónimo de Alexander Cabanel en el Musée Fabre de Montpellier, protagonizado por un Lucifer desnudo, postrado sobre el suelo con las manos entrelazadas cubriendo su rostro. La interpretación de Esquivel es, como en otras ocasiones, muy personal, pues el ángel se muestra de pie, con las manos en la misma posición que en el caso de Cabanel, pero vestido y con el rostro lleno de ira. La historiografía ha identificado como dos bocetos "del ángel bueno" y "del ángel malo" las menciones que Amador de los Ríos hace de dos obras en las colecciones de Manuel

\footnotetext{
${ }^{41}$ José Fernández de la Vega, "Pintura", Revista de teatros, 2 de mayo de 1841, 35-36. Citado en Banda, Antonio María Esquivel..., 77.

${ }^{42}$ Se conserva fotografía del cuadro (que no ha podido ser localizado) en el expediente del Legado Cimera (AMP, caja 100, leg. 16.12, exp. 7).
}

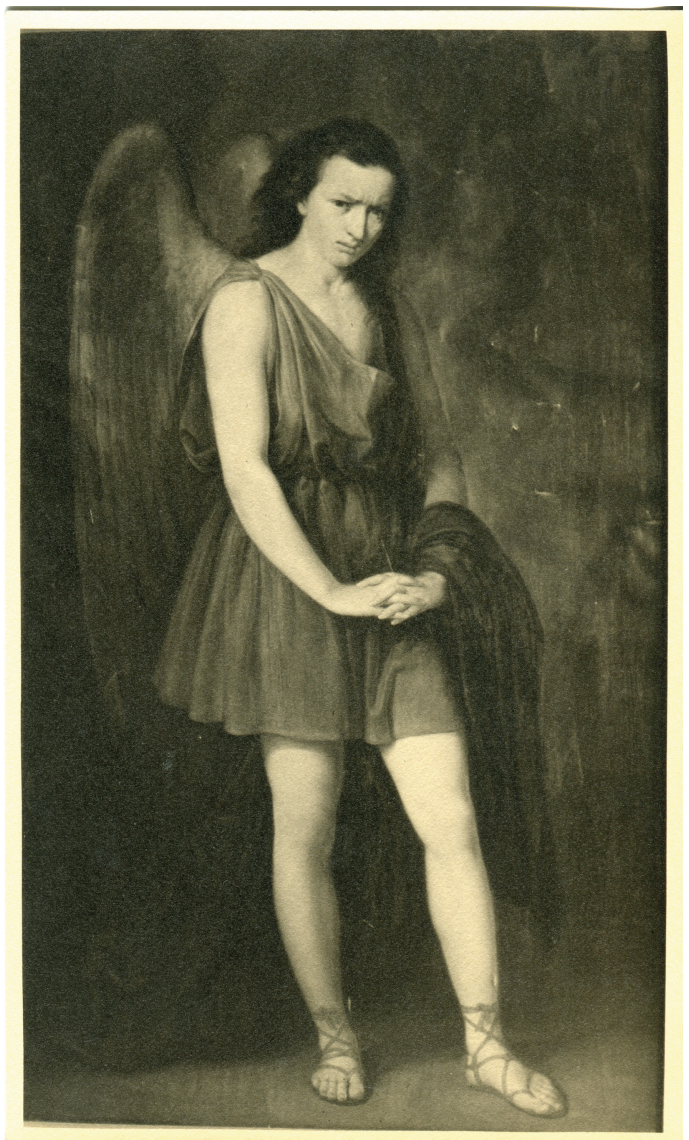

- Fig. 5. Antonio María Esquivel. El ángel malo. Hacia 1840. Reproducción fotográfica en Archivo del Museo del Prado.

López Cepero y de Jorge Díez Martínez ${ }^{43}$, a pesar de que ese autor identifica claramente ambas como bocetos para Luzbel ${ }^{44}$. Uno de ellos es el dedicado a Cepero (1839, colección particular $)^{45}$, mientras que el otro no se ha podido identificar y no parece que se corresponda con la obra conservada en el Santuario de Loyola de la que se tratará más adelante.

El tema del ángel caído o del ángel malo parece también estar representado en una de las pinturas que ornan el taller imaginario

\footnotetext{
${ }^{43}$ Guerrero, Antonio María Esquivel..., 26 y Banda, Antonio María Esquivel..., 76.
}

${ }^{44}$ José Amador de los Ríos, Sevilla pintoresca o descripción de sus más célebres monumentos artísticos (Sevilla: Francisco Álvarez y Cª , 1844), 456 y 489.

${ }^{45}$ Martínez Plaza, "Manuel López Cepero...", 556, fig. 8 . 
de su conocido retrato colectivo de Los poetas contemporáneos de 1846 (Museo del Prado). Nótese que si bien el pintor incluyó -a modo de boceto- otras obras de su mano, esta es la de mayor tamaño, lo que indica su relevancia. Aunque se ha identificado como el Juicio Final $^{46}$, se trata en realidad de una visión del infierno cuyo espacio central estaría ocupado por el demonio o Lucifer, y quizá quisiera representar $L a$ caída de los ángeles réprobos al infierno (Fig. 6). Las figuras que pueblan esta visión tienen connotaciones demoniacas $\mathrm{y}$ brujescas más propias de los temas de aquelarres (como el macho cabrío y la escoba), que también interesaron al artista en alguna ocasión. Así lo demuestra un aguafuerte inédito $^{47}$, posiblemente prueba única, firmado a pluma y que es también un dechado de desnudos en la que Satanás recibe sentado a una joven doncella. Este grabado refleja su interés por los temas de brujería, que, aunque hasta ahora se desconocía, permiten entender mejor algunas de sus interpretaciones escatológicas, como esta que nos ocupa.

Esquivel también cultivó el asunto del viaje del alma al cielo en varias ocasiones. Un lienzo de 1842 representa a El ángel de la guarda llevando un alma al cielo (colección particular $)^{48}$. El carácter ascensional de las figuras y su relación tanto con ejemplos franceses como con su obra Los ángeles liberando las almas del Purgatorio (1850, Sevilla, Museo de Bellas Artes) confirma que se trata de este tema y no de una simple representación del ángel de la guarda, iconografía que muchos pintores andaluces siguieron trabajando en el siglo XIX y que remitía, en todos los casos, a los modelos murillescos. En cambio, este cuadro, cuyo boceto preparatorio salió al

\footnotetext{
${ }^{46}$ José Luis Díez García, “Antonio María Esquivel. Los poetas contemporáneos", en El siglo XIX en el Prado, coord. por José Luis Díez García y Javier Barón (Madrid: Museo del Prado, 2007), 155.

${ }^{47}$ Biblioteca Nacional de España, INVENT/13279. Grabado en Siglo XIX, enero de 1838.
}

${ }^{48}$ Reproducido en Valdivieso y Fernández, Pintura romántica..., 110.

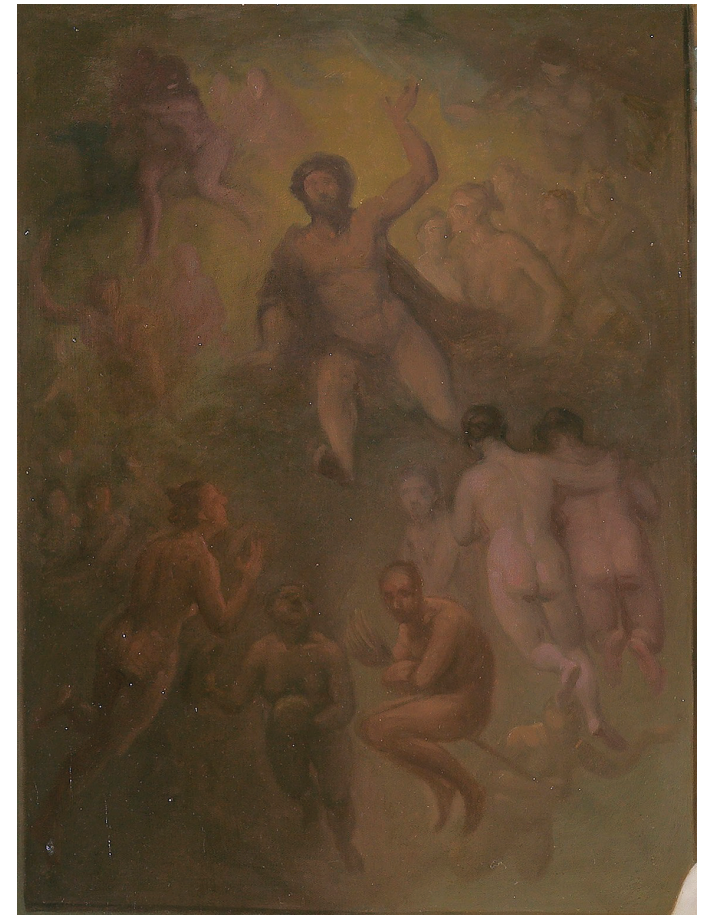

- Fig. 6. Antonio María Esquivel. La caída de los ángeles réprobos al infierno (detalle del cuadro de Los poetas contemporáneos). Museo del Prado, inv. P-4299.

mercado hace unos años ${ }^{49}$, muestra a un alma ascendiendo con la ayuda de un ángel, que lo toma con su brazo izquierdo. El referente en ambos casos se encuentra en Francia. Allí, artistas como Joseph Roques, Garnier Etienne Barthélémy y Jean Jacques Bestieu habían representado en el primer tercio del siglo a los ángeles rescatando del purgatorio a las almas -que a veces visten una túnica blanca y otras, sin embargo, aparecen desnudas- $y$ su subida al cielo. Aunque no es posible concretar si Esquivel pudo conocer las obras de alguno de estos pintores, su iconografía nada tiene que ver con los cuadros de ánimas tan habituales en las iglesias sevillanas, en los que la mitad superior está siempre reservada para la representación de la Trinidad, de la Virgen o de otro intercesor. Aquí interesa sobre todo el momento del rescate del alma por parte de los ángeles, que, como en otras de sus obras angélicas, señalan con una de sus manos al cielo, obviándose la presencia de cualquier mediador.

\footnotetext{
${ }^{49}$ Mercado del arte, $2002,31 \times 21 \mathrm{~cm}$
} 
Estas obras, además, son una reflexión acerca del consuelo y del amparo de la Fe. Este es el asunto del que sin duda puede considerarse el cuadro más singular de toda la producción religiosa de Esquivel: Una niña expirando en los brazos de la fe cristiana (Fig. 7), que no consta que fuera presentado en ninguna exposición pública. De hecho, su primera noticia documental es de 1893, cuando fue ofrecido por Teresa Arrazola Guerrero, viuda de Marcilla, al Estado, y la Academia informó favorablemente por ser "de lo mejor que produjo su pincel" ${ }^{50}$. El tema había sido tratado años atrás por algunos seguidores franceses del movimiento nazareno, como Emile Signol, en La religión cristiana acude en socorro de los afligidos (1836, Lubersac, iglesia de San Sebastián). El tipo de composición -con la figura adulta de tres cuartos y la niña sin mostrar los pies- y los rasgos e indumentaria de los personajes parecen remitir más concretamente a algunas obras de Edouard Jolin, como Le voeu d'une mére pour sa fille y L'action de grâce, que se grabaron en el Moniteur des arts en 1845 y que bien pudieron llegar a las manos de Esquivel.

Otro grupo temático importante es el de las Vírgenes con niño, del que se conocen al menos tres versiones. La más antigua, desconocida hasta su reciente aparición en el mercado del arte $^{51}$, es también la más cercana a los prototipos murillescos, en especial a la Virgen del Rosario o Del Escorial, que se encontraba desde 1827 en el Museo del Prado: ambas se disponen ante un fondo neutro y remarcan el carácter maternal de María. Existen otras dos interpretaciones más tardías: una en Patrimonio Nacional, de 1848, y otra en el Museo del Prado, de 1856, de la que se conoce un boceto, inédito, que salió a subasta en $1992^{52}$. En estas pinturas la conmovedora representación terrenal de fi-

${ }^{50}$ ARABASF, leg. 4-61-3. Solicitud de la Dirección General de Instrucción Pública, con fecha de 6 de marzo, e Informe de la Academia, de 3 de mayo.

${ }^{51}$ Subastas Isbilya, Sevilla, junio de 2016, lote 92.

52 Subastas Ansorena, Madrid, diciembre de 1992, lote 64 .

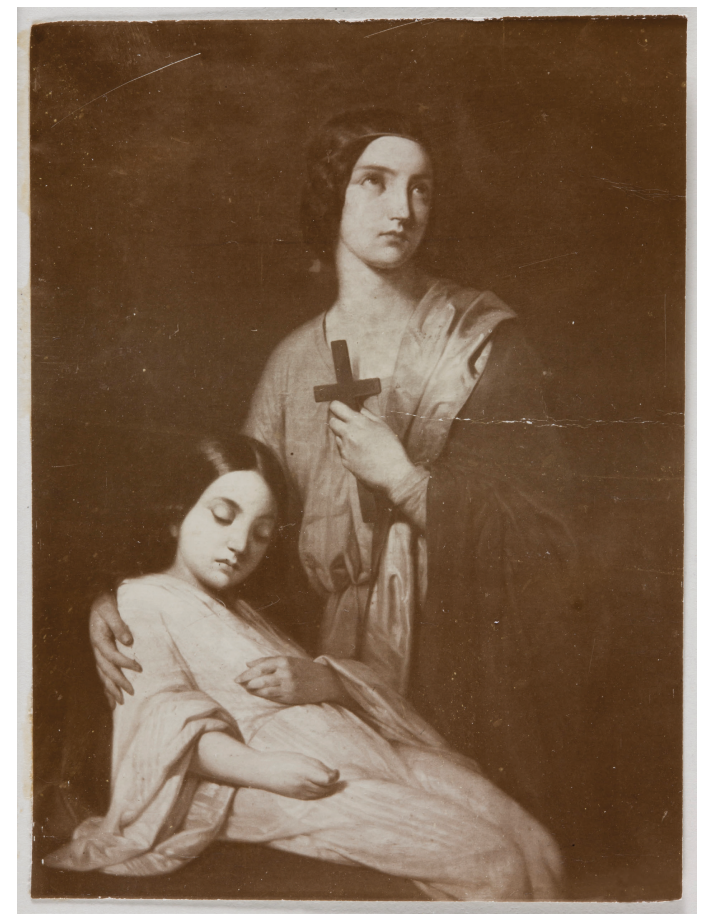

- Fig. 7. Antonio María Esquivel. Una niña expirando en los brazos de la fe cristiana. Hacia 1850. Museo del Prado, inv. I-1140.

liación murillesca ha dejado paso a una verdadera manifestación del niño Jesús como Salvator Mundi, rodeada de una abundante presencia angelical, que acerca estas pinturas al tipo conocido como Hodigitria, en el que María señala a Cristo como Salvador. A diferencia de la primera versión, en estas otras dos la Virgen no acoge cálidamente al niño, sino que lo señala o sirve de trono, mientras este se ofrece victorioso y porta una cruz, elemento que se incorpora ahora y que pensamos remite a los niños pasionarios tan frecuentes en el mundo devocional andaluz. A este tipo de imágenes debía también aludir otra obra que no conocemos, pero que presentó a la Exposición Nacional de Bellas Artes de 1856 -junto con la Virgen del Prado mencionada- titulada El niño Jesús con la cruz y una corona de espinas en la mano. Aquellas y esta abundan en la representación del Niño como Salvador y Redentor. 


\section{LA FORTUNA DE SUS PINTURAS RELIGIOSAS: VERSIONES Y COPIAS}

El pintor fue consciente del éxito inmediato que tuvieron algunas de estas obras religiosas y se ocupó de replicarlas o versionarlas con ligeros cambios, siempre a un tamaño mucho menor. Esto último ha ocasionado que en más de una ocasión estos pequeños cuadros hayan sido considerados bocetos, cuando en realidad creemos que se trata de obras realizadas con posterioridad. Es el caso de La caída de Luzbel que conserva el Santuario de Loyola (Guipúzcoa), publicada como trabajo preparatorio ${ }^{53}$. El único cambio entre este y el cuadro definitivo es la espada que porta San Miguel en la mano derecha. Pero la composición, y el resto de elementos, como los colores, el vuelo de los paños y la posición de las figuras son idénticos en ambas obras, que además están firmadas en el mismo año de 1840. Además, ya hemos dicho que existe una versión anterior de este tema, firmada en 1839 (colección particular), previo al cuadro definitivo, que sí se trata de un boceto. Sin duda, el éxito inmediato del Luzbel del Liceo hizo que el propio artista tuviera que replicarlo en la obra de Loyola ${ }^{54}$.

Similares problemas presenta El Casto José que posee el Museo de Córdoba (Fig. 8), silenciado en la bibliografía del pintor. Su composición recuerda al cuadro del mismo título del Museo de Bellas Artes de Sevilla, de 1854, pero con algunos cambios en la posición de los brazos de las dos figuras y en el cortinaje del fondo, mucho más efectista y alegre en la versión cordobesa. La obra posee en su reverso una inscripción, cuya grafía es diferente a la de Esquivel, en la que se señala que se trata de una "reproducción en menor escala", "ejecutada por él mismo". Aunque

${ }^{53}$ Pedro María Montero e Ignacio Cendoya, "La gestación de una obra emblemática en la producción de Antonio María Esquivel", Archivo hispalense: Revista histórica, literaria y artística, no 227 (1991), 197-208.

${ }^{54}$ Puesto que se desconoce la procedencia del cuadro (consulta realizada al Archivo y Biblioteca del Santuario de Loyola, 21 de septiembre de 2018) no se puede estudiar su origen.

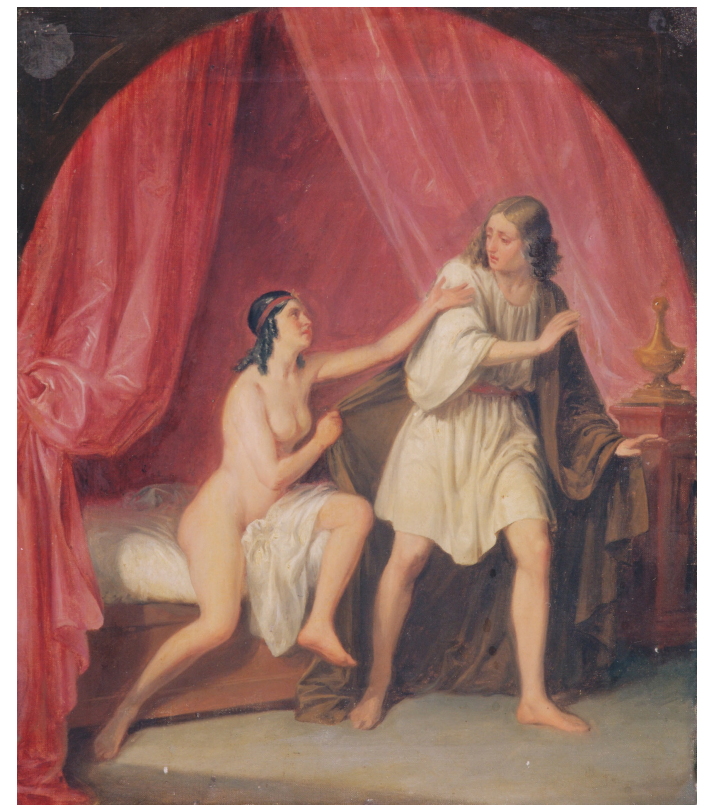

- Fig. 8. Antonio María Esquivel. El Casto José. 1856. Museo de Córdoba, inv CE2550P.

la obra no está firmada, se publicó un grabado de la misma en 1856, acompañado de un pequeño texto aclaratorio que confirma que se trata de un cuadro que realizó Esquivel para una rifa benéfica organizada en febrero de ese año por la Sociedad Protectora de las Bellas Artes ${ }^{55}$, que él había contribuido a fundar. Cabe pensar que bien en el seno de esta, o anteriormente en el Liceo, también replicase algunas otras obras, que sin duda acabarán viendo la luz.

Por otro lado, a partir de la década de 1840, Esquivel fue convirtiéndose en una figura de referencia en la Corte para los jóvenes pintores, como evidencian las copias manuscritas de su manual de Anatomía pictórica $(1848)^{56}$ y de sus diversas láminas ${ }^{57}$. Puesto que Esquivel concibió algunas de sus obras religiosas con un fin claramente didáctico, es normal que abunden las copias de estas, muchas de ellas anónimas. Es el caso de la

\footnotetext{
${ }^{55}$ La Ilustración, 25 de febrero de 1856, 80.

${ }^{56}$ Es el caso de la copia de Mariano Baquero (Museo Nacional del Romanticismo) y de otra anónima (Museo del Prado, Biblioteca).

${ }^{57}$ Pueden destacarse las copias del pintor Martín Rico Ortega (Museo del Prado).
} 
Judith con la cabeza de Holofernes (mercado del arte, 2018), aparecida recientemente y que sigue el original que ahora está en el Museo Nacional del Romanticismo.

Resulta más interesante conocer que algunas de estas copias tuvieron un destino devocional. Entre todas ellas sobresalen las del cuadro de Santa Justa y Rufina (Museo Nacional del Romanticismo), cuyas novedades compositivas e iconográficas no impidieron que se copiase en numerosas ocasiones ${ }^{58}$. La obra de la parroquia matriz de la Concepción de La Laguna ha sido atribuida al propio pintor $^{59}$, si bien parece tratarse de una copia, pues no está firmada y su calidad resulta inferior. En el mismo entorno del taller se debió hacer otra copia, esta vez tan solo de las figuras de las santas hasta la cintura, que salió al mercado en $2017^{60}$. El propio José Gutiérrez de la Vega, paisano y compañero de Esquivel en Madrid, la copió a un tamaño muy reducido (Sevilla, colección particular $)^{61}$, suprimiendo algunos elementos. También debemos señalar una obra muy posterior, conservada en el presbiterio de la iglesia de San Bartolomé, en Paterna del Campo (Huelva), puesto que justifica, como ninguna otra, el verdadero éxito de esta composición. Se trata de un cuadro anónimo, fechable entre 1860 y 1870 , que representa a las santas también sentadas y abrazadas, con los rostros elevados al cielo y acompañadas de los elementos cerámicos, que igualmente se disponen a la izquierda. Aunque el colorido de sus ropajes resulta más animado y no hay aparición angélica, cabe pensar que el mode-

${ }^{58}$ Algunas de esas copias aparecen mencionadas en Pérez Calero, "Consideraciones estéticas...", 533, nota 19 y Carlos González Navarro, "Antonio María Esquivel. Santas Justa y Rufina", en Murillo y su estela en Sevilla, coord. por Benito Navarrete (Sevilla: Ayuntamiento de Sevilla, 2017-2018), 288-290.

${ }^{59}$ Antonio de la Banda y Vargas, "Un posible Esquivel en la Parroquia de la Concepción de La Laguna", Archivo Hispalense, $\mathrm{n}^{\mathrm{o}} 186$ (1978), 183-185.

${ }^{60}$ Subastas Ansorena, Madrid, 31 de enero de 2017, lote 200 y 23 de mayo de 2017, lote 125: 124 × $96 \mathrm{~cm}$.

${ }^{61}$ Inventariada en el Registro del Patrimonio Mueble de Andalucía, código 94150. lo en el que se fijó su autor fue el consabido cuadro de Esquivel.

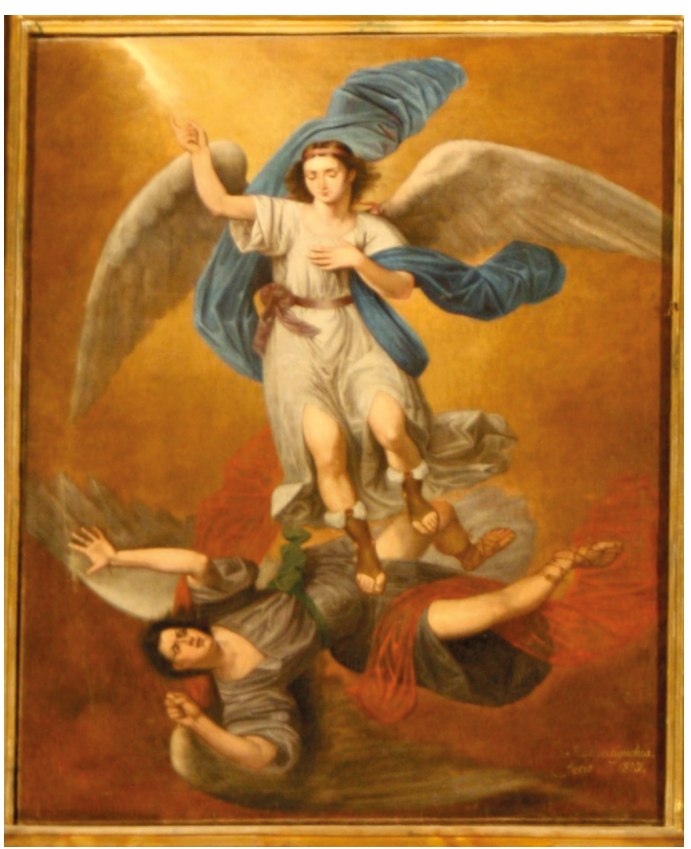

- Fig. 9. Javier Mendiguchía. La caída de Luzbel (copia de Esquivel). 1847. La Puebla de Montalbán, iglesia de Nuestra Señora de la Paz. Foto del autor.

El otro cuadro que tuvo especial éxito fue el de La caída de Luzbel. Se conocía ya una copia anónima ${ }^{62}$ y la estampa abierta por Gaspar Sensi, fiel al original. Aquí damos a conocer una nueva (Fig. 9), que muestra mejor que ninguna otra su fácil conversión en una imagen devocional. Ocupa el lugar central en el retablo de la Iglesia parroquial de San Miguel y de la Virgen de la Paz, en La Puebla de Montalbán (Toledo). Firmada y fechada por Javier Mendiguchía en 1847, debió ser encargada por Bernardino Fernández de Velasco, quien, entre otros títulos, ostentaba el de VIII conde de la Puebla de Montalbán. El noble había sido retratado un año antes por el propio Esquivel en Los Poetas contemporáneos y a él pertenecía esta iglesia, anexa al palacio que aún conservan sus descendientes en esta localidad. Desconocemos los motivos por los que la copia se encargó a este pintor, casi desconocido, y no al propio

62 VV.AA., Pintura del siglo XIX en España (Pamplona: Arteclío, 1993), 43. 
Esquivel o a su hijo Carlos María, pero debió ser realizada para figurar de forma específica en ese encasamento, posiblemente como sustitución de otra anterior. Por su envergadura y el lugar al que fue destinada, indica como ninguna otra el éxito del Luzbel.

Por último, de su entorno más cercano proceden numerosas obras que bien copiaron algunos de sus cuadros de santos -como el San Hermenegildo que realizó José Amador de los Ríos (Museo del Prado)- o en cambio tomaron este modelo para sus propias pinturas. Es el caso de la Santa mártir de Carlos María Esquivel (Patrimonio Nacional, Palacio de Riofrío), fiel secuela del modelo de imagen devocional implantada por el padre.

\section{CONCLUSIONES}

El estudio de la pintura religiosa de Esquivel, quien a menudo ofrece nuevas versiones sobre algunos de los asuntos más frecuentes en la tradición cristiana y a su vez explora nuevos temas, revela cómo el sevillano buscó renovarse de forma constante no solo como retratista y nos sugiere nuevas vías de interpretación de su obra en el contexto del Romanticismo español. Considerado a menudo como fiel defensor del legado pictórico del Siglo de Oro, muchas de estas pinturas, sin embargo, evidencian, de forma clara, una relación con el arte contemporáneo extranjero, en especial francés, y, con ello, su cercanía a algunos de los temas habituales entre los nazarenos, corriente a la cual, sin embargo, él se opuso de forma expresa.

Su predilección por determinados temas o la renovada lectura que ofrece de otros tantos pueden resultar incluso insólitos, sobre todo si se le compara con sus colegas españoles. Este análisis, por tanto, permite ponderar mejor sus aportaciones y demuestra que su relevancia en el devenir de la pintura decimonónica no se debe solo a cuestiones meramente estilísticas. Además, las numerosas copias y versiones de sus obras religiosas ponen de manifiesto la validez de algunas de sus interpretaciones iconográficas y la fortuna que estas tuvieron no solo en otros artistas sino también en el contexto cultural y devocional español.

\section{BIBLIOGRAFÍA}

Amador de los Ríos, José. Sevilla pintoresca o descripción de sus más célebres monumentos artísticos. Sevilla: Francisco Álvarez y Ca, 1844.

Banda y Vargas, Antonio de la. “Un posible Esquivel en la Parroquia de la Concepción de La Laguna". Archivo Hispalense, no 186 (1978), 183-185.

Banda y Vargas, Antonio de la. Antonio María Esquivel. Sevilla: Diputación Provincial, 2002.

Castillo, Jaime. La iglesia de Chamberí. Madrid: Edieco S.L., 1999.

Díez García, José Luis. "Antonio María Esquivel. Los poetas contemporáneos". En El siglo XIX en el Prado, coordinado por José Luis Díez García y Javier Barón, 154163. Madrid: Museo del Prado, 2007.

Fernández de la Vega, José. "Pintura". Revista de teatros, 2 de mayo de 1841, 35-36.

González Navarro, Carlos. "Antonio María Esquivel. Santas Justa y Rufina". En Murillo y su estela en Sevilla, coordinado por Benito Navarrete, 288-290. Sevilla: Ayuntamiento de Sevilla, 2017-2018.

Guerrero Lovillo, José. Antonio María Esquivel. Madrid: CSIC, 1957.

Madrazo, Pedro de. "Esposición [sic] de pinturas de 1847. Artículo II". Semanario Pintoresco, no 46 (1847), 361-364.

Martínez Plaza, Pedro J. “Manuel López Cepero (1778-1858) y la pintura sevillana de su tiempo". Laboratorio de Arte, no 29 (2017), 543-566.

Montero, Pedro María e Ignacio Cendoya. "La gestación de una obra emblemática en la producción de Antonio María Esquivel". Archivo hispalense: Revista histórica, literaria y artística, no 227 (1991), 197208. 
Navarrete, Esperanza. La Academia de Bellas Artes de San Fernando y la pintura en la primera mitad del siglo XIX. Madrid: FUE, 1999.

Ossorio, Manuel. Galería de artistas españoles del siglo XIX. Madrid: Imprenta de Moreno y Rojas, 1883-1884.

Pantorba, Bernardino de. "Antonio María Esquivel". Arte Español, T. XXII (1959), 155-179.

Pérez Calero, Gerardo. "Consideraciones estéticas en torno a la obra del pintor Antonio M. Esquivel". Laboratorio de Arte, no 24 (2012), 527-536.

Pérez Morera, Jesús. “Simbología masónica del retablo mayor de la Iglesia de El Salvador de Santa Cruz de la Palma (Canarias)". Cuadernos de Arte e Iconografía, no 8 (1991), 260-266.

Pérez Sánchez, Aránzazu. El Liceo Artístico y Literario de Madrid (1837-1851). Madrid: FUE, 2005.

Quintero, Pelayo. “Cuadros inéditos de José [sic] María Esquivel que se conservan en Cádiz". Boletín del Museo de Bellas Artes", no 7 (1923), 79-88.
Tejada Vizueta, Francisco. "Las artes plásticas. La pintura". En La catedral de Badajoz. 1255-2005, coordinado por Francisco Tejada Vizueta, 486. Badajoz: Tecnigraf Editores, 2007.

Valdivieso, Enrique. Pintura sevillana del siglo XIX. Sevilla: el autor, 1981.

Valdivieso, Enrique. Historia de la pintura sevillana: siglos XIII al XX. Sevilla: Guadalquivir, 1986.

Valdivieso, Enrique y José Fernández. Pintura romántica sevillana. Sevilla: Fundación Sevilla Endesa, 2011.

Velaz de Medrano, Eduardo. "Revista de Nobles Artes. Esposición [sic] del Liceo. Artículo II (1)". La España, 5 de julio de 1848.

Velaz de Medrano, Eduardo. "Revista de Nobles Artes. Esposicion [sic] de pinturas, articulo I". La España, 7 de octubre de 1849.

Villanueva, Luis. "Don Antonio María Esquivel". Museo de las Familias, T. II (1844), 90-93.

VV.AA. Pintura del siglo XIX en España. Pamplona: Arteclío, 1993. 